\title{
A MEGAFALHA DE CUBATÃo NO SUDESTE BRASILEIRO
}

G.R. Sadowski ${ }^{1}$

\section{RESUMO}

O conjunto de falhas, conhecidas como transcorrentes, que bordeja a costa sudeste brasileira envolvendo as falhas denominadas de Cubatáo, Além-Paraíba, Laneinha, Itapeúna, etc., constitue parte de um Sistema de Falhamento de mais de $2.000 \mathrm{~km}$ de extensáo com evoluçáo e estruturação complexa, ao qual designamos de Sistema de Falhamento Cubatáo ou Megafalha do Cubatão.

A falha do Cubatāo propriamente dita, apresenta divisão longitudinal em segmentos cujas deformaçōes expōem diferentes níveis estruturais. O segmento sudoeste do lineamento é representativo do nível estrutural superior e, conforme avançamos para NE, passa a afetar rochas mais profundas, com o surgimento de estruturas características de deformaçăo própria a níveis inferiores.

A junção da falha com o falhamento de Taxaquara é controvertida no seu desenlace. Os dados existentes indicam que esta última parece ser a feiçăo dominante.

Os indícios texturais e tectoglifos de deformação mostram, para a falha de Cubatăo, uma evoluçăo extremamente complexa desde falhamento inverso até transcorrente destral e sinistral, como normal a obliqüo. Cataclasitos com evidências de recristalizaçâo posterior com imposiçāo de novas xistosidades bem demonstram tal aspecto.

As idades de rochas figneas afetadas variam desde o Proterozóico Superior até o Mesozóico. Reativaçōes chegam a afetar sedimentos do Cenozóico. E, há evidencias, embora ainda tênues, de movimentaçáo atual ao longo de falhas de direção NW que nấo pertenceriam ao Sistema.

Em termos de compartimentaçăo tectônica antiga, tem-se a impressáo que ocorre um afinamento da crosta na sua porçâo sudeste. O sistema de falhamentos ter-se-ia originado no mecanismo de colisão e subsequente tectônica de escape entre os Crátons Angolano e de São Francisco.

${ }^{1}$ Departamento de Geologia Geral, Instituto de Geociências/USP, Sảo Paulo. 


\section{ABSTRACT}

The Cubatāo Megafault System represents an extensive strike slip system exposed along about $800 \mathrm{~km}$ with a minimum breadth of about $150 \mathrm{~km}$ and a maximum of 350 $\mathrm{km}$ when considered as part of the Socorro-Guaxupe thrust wedges. The main fault zone is represented by the Cubatão-Além Paraíba and Lancinha faults. The extension of this fault zone has been detected beneath the sediments of the Parana Basin for at least an additional $1,200 \mathrm{~km}$ implying a length of more then $2,000 \mathrm{~km}$, which is longer than the San Andreas fault. The fault affects different structural levels of the crust and has exhibited different behaviour throughout its history of activity. It was essentially ductile at depth during the Proterozoic where deep granulites were dragged about $40 \mathrm{~km}$ along the Alem Paraiba fault segment. The mylonites are folded and show an overprinted schistosity marked by neocrystallized biotites of Proterozoic age. The drags show the effect of right lateral kinematics during this phase; however left lateral activation is suggested by the distribution of a pattern of secondary faults related to later events. The fault system is offset at its intersection with the NW striking Guapiara, Ubatuba and Cabo Frio-Poços de Caldas Lineaments. The Cubatâo fault sensu strictu shows a controversial thrust-strike slip pair envolving a wedge of low grade metamorphic rocks. Oblique slip and transtensional basin formation envolved the fault system during the Tertiary and originated the Serra do Mar Rift. Plots of earthquake activity show that NW striking faults which cut the system transversally are still being activated. The origin of this enormous transcurrency may be related to a collision between Proterozoic cratonic masses and consequent escape tectonics or, oblique subduction effects.

\section{INTRODUÇĀO}

A geologia do sudeste brasileiro vem sendo palco de um número crescente de inovaçôes em termos de modelos tectónicos e dados nestes últimos dez anos. A estruturaçẩo do arcabouço tectônico está se mostrando aparentemente bem diversa da pressuposta anteriormente. Os aspectos mais notáveis sāo, por mais estranho que pareça, aqueles levantados pelos pesquisadores pioneiros. O Grupo São Roque aparentemente seria correlato cronologicamente a rochas da Série Minas e ao Açungui e com idades de deposiçăo prébrasilianas. Empurrôes propostos por EBERT (1968) foram redescobertos com o nome de Sistema de Nappes Socorro-Guaxupe (CAMPOS NETO \& VASCONCELLOS, 1985). Por outro lado, nota-se uma tectônica rúptil razoavelmente ativa durante o Fanerozóico pré e pós abertura do Atlantico (ZALAN et al., 1987; SADOWSKI, 1987). No que diz respeito a tectónica rúptil, as seguintes feiçōes merecem destaque estando talvez relacionadas direta ou indiretamente:

a. O sistema de meganappes Socorro-Guaxupé.

b. O sistema de falhamentos transcorrentes que designamos Cubatăo 
(SADOWSKI \& MOTIDOME, 1987), ativo desde o Pré-cambriano.

c. O sistema de falhas da borda da bacia costeira de Santos.

d. O sistema de rift terciário da Serra do Mar (ALMEIDA, 1975).

e. O conjunto de lineamentos e enxames de diques de direçáo NW correspondentes ao arco de Ponta Grossa, Lineamentos Guapiara, Ubatuba e Cabo Frio-Poços de Caldas (SADOWSKI, 1987) ao qual correspondem algumas feiçôes possivelmente ativas durante o Cenozóico até o presente.

\section{EXTENSĀO}

O Sistema Cubatấo inclue várias zonas de cisalhamento extensas, subparalelas e com caracteristicas semelhantes, sendo geralmente miloníticas de alto ângulo e com direçōes oscilantes entre $\mathrm{N} 30 \mathrm{E}$ a N70E. Várias apresentam evidências de cisalhamento direcional. Possuem nomes locais tais como Freires, Agudos Grandes, Ribeira, Itapeúna, Boquira, Taxaquara, Caucaia, Jaguari, Além Paraíba, Lancinha, Cubatâo, etc. Este Sistema se estende em largura, desde o Atlântico até a borda Sul-Sudeste do Estado de Minas Gerais, por cerca de $300 \mathrm{~km}$, no caso de envolver as cunhas de empurrăo Socorro-Guaxupé, ou então, até aos arredores do falhamento de Jandiuvira na borda da cunha de Socorro, totalizando $150 \mathrm{~km}$ de largura. Há dúvidas em se sobrepor estes dois sistemas, transcorrente e de empurrão, podendo eventualmente estar associados num sistema de tectonica de escape ou, entăo, corresponderem a dois eventos tectônicos distintos, o primeiro de cavalgamento e, o segundo, transcorrente.

O termo "transcorrente" nem sempre parece adequado à primeira vista, pois foi introduzido por ANDERSON (1951) para indicar falhas que cortam ou truncam estruturas ou dobramentos. No caso em questão, o arrasto dúctil das estruturas para dentro e paralelamente à zona de cisalhamento torna difícil a definição deste truncamento no campo.

O Sistema Cubatăo apresenta, como zona de falhamentos principal, o alinhamento de três segmentos de falha: Lancinha-Itapeúna, Cubatáo e Além Paraíba. O comprimento exposto é de cerca de $800 \mathrm{~km}$. A falha se estende por cerca de mais $1300 \mathrm{~km}$ sob a Bacia do Paraná (ZALAN et al., 1987) até o Estado do Rio Grande do Sul, totalizando mais de $2000 \mathrm{~km}$ de extensăo.

\section{LOCALIZAÇÃo TECTÔNICA}

A zona de falha Lancinha-Cubatâo-Além Paraíba ou simplesmente Cubatão, separa o conjunto de rochas de alto grau dominante dos blocos Costeiros e Itatins (ou Joinville) do conjunto de rochas a NW, portador de diferentes associaçốes metamórficas.

O bloco Itatins apresenta estruturas arqueadas ("arcuate") com convexidade 
para W, sendo constituído por maciços granulíticos arqueanos entremeados por algumas faixas metassedimentares de baixo grau de idade indefinida e limitados a Nordeste pela falha de Itariri. O bloco Costeiro apresenta rochas de idade Brasiliana. O conjunto de blocos a NW da falha é representado por metassedimentos Açungui-Sáo Roque de deposiçáo possivelmente atribufvel ao Proteroz6ico Médio e por maciços antigos pré-brasilianos e, inclusive arqueanos, entremeados por granitóides brasilianos.

A zona de falha de Cubatáo apresenta-se segmentada nas seguintes porções na área de embasamento exposto (Fig. 1):

Segmento Lancinha - se estende da bacia do Paraná até a planície aluvionar do baixo Ribeira sendo interrompido (?) pelo Lineamento de Guapiara onde, no local de Sete Barras, foi definido um graben com cerca de $350 \mathrm{~km}$ de sedimentos Cenozóicos. O segmento Lancinha corta rochas de baixo grau metamorfico o qual passa a ser mais intenso a NE.

Segmento Cubatâo "sensu strictu" - onde a falha se apresenta associada a uma faixa de metassedimentos de baixo grau. Estende-se desde a baixada do Ribeira até as proximidades de reservatório de Ponte Nova onde é desviado por efeito de um lineamento NW (Ubatuba; RIDEG, 1974). A partir deste trecho ocorre complexidade crescente até o ponto de convergência com a falha de Taxaquara (tal como proposta por HASUI et al., 1978, que designamos como Taxaquara I face à possível controvérsia da extensão da Taxaquara até este local). Neste trecho, a Norte de Paraibuna, fica-se na dúvida sobre qual a falha dominante após o cruzamento destas duas feiçóes. No entanto, observa-se a continuidade do bloco de metassedimentos cavalgado dentro da zona de falha, típico da falha de Cubatâo. Neste caso a falha de Cubatâo se estende até próximo à borda com o Estado do Rio de Janeiro, onde a falta de dados impede a caracterizaçăo da sua continuidade. Todavia, na imagem de Radar observase um "off set" aparente, escalonado ascendente, com a falha de Além Paraíba.

Segmento Além Paraíba - afeta rochas de alto grau metamórfico, com patente deformaçáo dúctil própria dos níveis estruturais profundos, com arrasto destral de cerca de 40 a $50 \mathrm{~km}$, visível em imagem de satélite.

A área de "off set" mereceria ser investigada em detalhe, pois os escalonamentos deste tipo podem resultar em zonas de achatamento e empurrôes no caso de falhas destrais e, de grabens rombicos do tipo transtracional ou "rombochasmos" no caso de falhamento sinistral.

A falha possue terminação em "splay" (em leque) ou rabo de cavalo, em direção ao Estado do Espírito Santo.

\section{EXPRESSĀO TOPOGRÁFICA}

A Megafalha do Cubatáo apresenta notável depressão topográfica linear associada à erosáo diferencial da faixa de metassedimentos associada à falha de Cubatăo, bem como na área dos milonitos, tanto da falha de Além Parába como na Lancinha. Na área da 


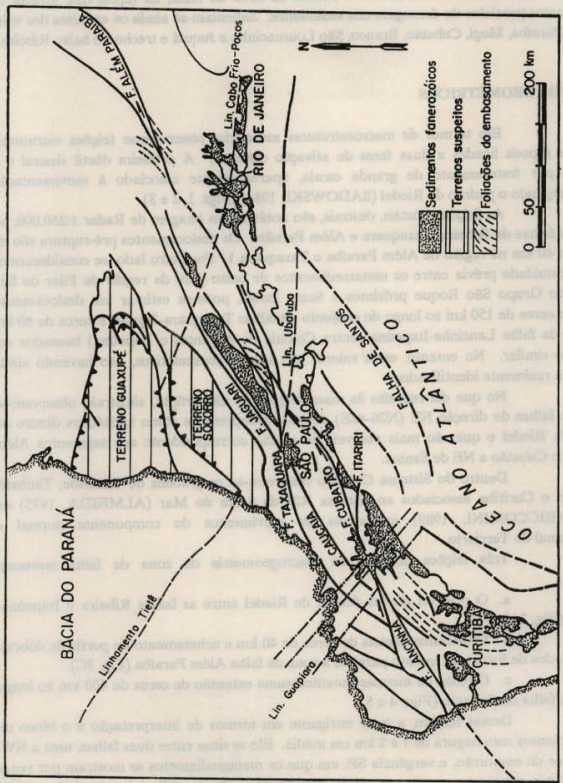

哭 
borda da Bacia do Paraná observa-se o reflexo da zona de falha, na topografia, através de alinhamentos paralelos da drenagem nos sedimentos. Salientam-se ainda os encaixes dos vales dos rios Paraíba, Mogi, Cubatão, Branco, São Lourencinho e Juquiá e trecho do baixo Ribeira.

\section{ASPECTOS GEOMETRICOS}

Em termos de macroestruturas associadas observam-se feiçōes estruturais dúcteis e rúpteis ligadas a duas fases de ativação distintas. A primeira dúctil destral e a segunda, por fraturamento de grande escala, aparentemente associado à movimentaçáo sinistral segundo o padrāo de Riedel (SADOWSKL, 1984) (Figs. 1, 2 e 3).

As feiçōes dúcteis, destrais, são notáveis em imagem de Radar 1:250.000, ao longo das falhas de Ribeira, Taxaquara e Além Paraíba. Os deslocamentos pré-ruptura são da ordem de $40 \mathrm{~km}$ na regiáo de Além Paraiba e Taxaquara I. Por outro lado, se considerarmos uma continuidade prévia entre os metassedimentos de baixo grau da regiâo de Pilar do Sul, com os do Grupo São Roque próximos a Santa Isabel, pode-se estimar um deslocamento destral de cerca de $150 \mathrm{~km}$ ao longo do conjunto de falhas Taxaquara-Jaguari e cerca de $80 \mathrm{~km}$ ao longo da falha Lancinha-Itapeúna (entre Colônia de Abrantes e Itaperina) baseados em correlaçăo similar. No entanto, estes valores são apenas especulativos, năo havendo ainda níveis-guia realmente identificados.

No que diz respeito às macrofeiçóes de nível rúptil, sinistrais, observam-se fraturas e falhas de direçăo NE (N20-40E) destrais interpretadas como antitéticas dentro do modelo de Riedel e que são mais notáveis no trecho correspondente aos segmentos Além Paraíba e o Cubatão a NE de Santos.

Dentro do Sistema Cubatão observam-se os grabens de Rezende, Taubaté, São Paulo e Curitiba associados ao sistema Rift da Serra do Mar (ALMEIDA, 1975) ou Sudeste (RICCOMINI, 1989) indicativos de movimentos de componente normal e transtensional do Terciário.

Três feiçōes notaveis na macrogeometria da zona de falha merecem destaque:

a. O possfivel duplex destral de Riedel entre as falhas Ribeira e ItapeúnaLancinha (Fig. 2A).

b. Os arrastos dúcteis de cerca de $40 \mathrm{~km}$ e achatamento de perfis de dobras, acompanhados de forte estiramento paralelo à zona de falha Além Parafba (Fig. 3C).

c. O bloco de metassedimentos numa extensão de cerca de $400 \mathrm{~km}$ ao longo da zona de falha de Cubatáo (Figs. 4 e 5 ).

Destas feiçōes, a mais intrigante em termos de interpretação é o bloco de metassedimentos com largura de 1 a $3 \mathrm{~km}$ em média. Ele se situa entre duas falhas, uma a NW, com indícios de empurrăo, e vergência $\mathrm{SE}$, em que os metassedimentos se mostram por vezes cavalgados por gnaisses e granitos e, outra, que limita o bloco a SE, subvertical de caráter 


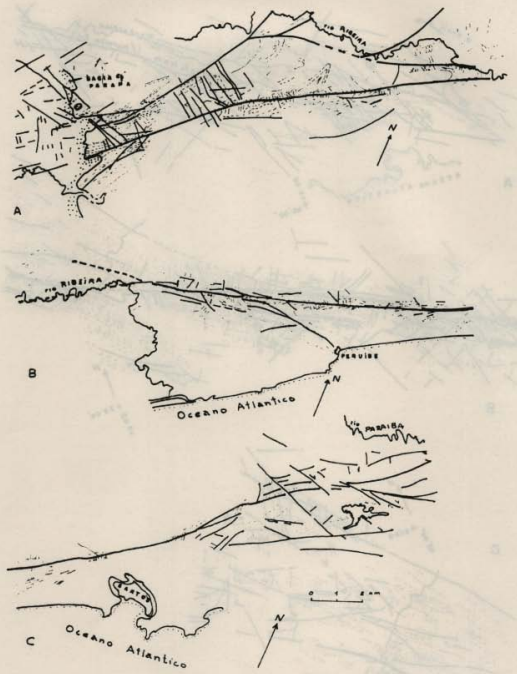

Figura 2 - Interpretaçāo de imagens a đistáncia dos padrōes estruturais do Sistema de Falhamento đe Cubatăo com Ênfase na Zona de Falha e feị̄ös associadas. Fraturas maiores em traço contínuo espesso e folią̧ōes em traço interrompido mais fino. De A para $C$ no sentido SW pare NE: A: Duplex de Riodel e reflexos na cobertura sedimentar, B: zona de interrupçăo na área do baixo Ribeira e entroncamento com a falha de Itariri; C: complicação e possível desvio cumulativo destral na área da Barragem Ponte Nova. Fonte: Interpretaçäo de imagens de Radar e Landsat. 

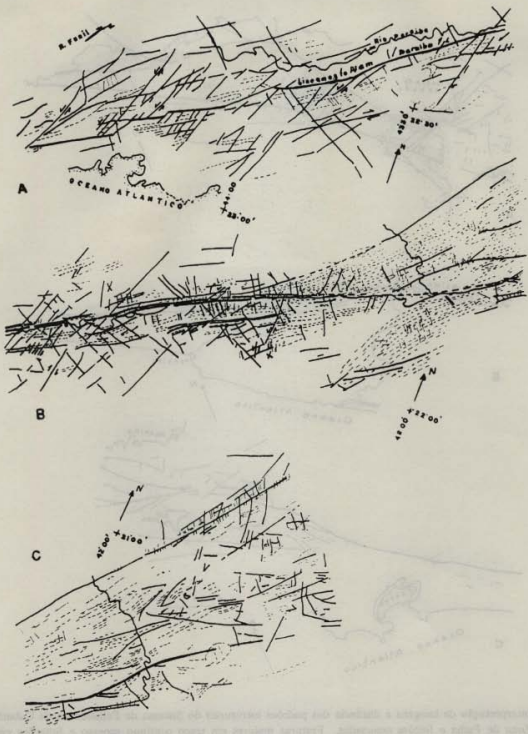

Figura 3 - Idem Figura 2; sucessivas imagens de SW para NE. A: Offset escalonado ascendente na região do eneontro com a Falha Além Paraiba; B. Arrasto dúctil de caráter destral; C: Tendência à dissipaçăo em "splay". Escala indicada,jigual para todas as figuras. Tracejado fino: foliaģoes; traço cheio: falhas. 
lateral (?). Os indícios de cavalgamento sẫo aparentes inclusive na microestrutura com estiramentos de mergulho na zona de falha, contradizendo uma mecânica transtracional $\mathrm{e}$ favorecendo mecanismos de transpressão.

As feiçōes geométricas, observadas até agora na microestrutura, mostram uma fase de forte estiramento horizontal na zona das falhas de Lancinha (Formaçăo Camarinha) e Além Paraíba, porém menos intenso em trechos da falha de Cubatăo.

Os dados de análise cinemática pelos métodos de análise de estrias e falhas são escassos, e se restringem à fase rúptil-friável, não sendo suficientes principalmente face a alguns resultados contraditórios, provavelmente associados à interseç̧ăo de estruturas originárias de diferentes reativaçōes. Algumas estruturas menores notáveis săo:

- Dobras em bainha de seçăo circular em quartzitos no falhamento Taxaquara I, com indicaçóes de estiramento horizontal tipo prolato. Tais dobras afloram em cortes da Rodovia dos Tamoios no Estado de Sáo Paulo.

- Lineaçăo de estiramento segundo o mergulho no trecho de cavalgamento do embasamento granito gnáissico sobre os filitos e xistos da faixa metassedimentar associada ao falhamento de Cubatăo, nas proximidades de Paraibuna.

- Transposiçăo no mínimo de $3^{\text {a }}$ fase de deformaçăo nos xistos e filitos cavalgados próximo a Paranapiacaba.

- Dobramento dos milonitos da zona de falha de Cubatão no trecho transcorrente, com xistosidade plano axial superimposta e salientada por biotitas recristalizadas (Vales dos rios Cubatão e Săo Lourencinho).

- Estruturação oblata nos grăos de quartzo em milonitos, em trechos da faixa milonítica na regiẫo de Cubatão.

- Estiramento subhorizontal linear intenso em conglomerados polimícticos da formaçăo Camarinha no Paraná (FASSBINDER, 1990).

- Deslocamento sinistral de $900 \mathrm{~m}$ na horizontal afetando diques de diabásio ao Norte de Curitiba na luz da falha de Lancinha (FIORI, 1985; in: FASSBINDER, 1990) e métrico em diques menores.

- Falta de deslocamento expressivo em enxames de diques mesozóicos que cortam a falha de Lancinha na área do arco de Ponta Grossa (regiăo de Pombas e arredores a NE de Curitiba) (FASSBINDER, 1990).

- Milonitização do granito de Paranapiacaba, datado em $480+60 \mathrm{Ma}(\mathrm{K} / \mathrm{Ar})$ (SADOWSKI, 1974) e de pegmatito brasiliano na regiăo de Très Rios (CAMPANHA, 1981).

\section{CINEMÁTICA PROVÁVEL}

Os dados existentes demonstram que a fase de deformação destrah, com componente dúctil, foi a mais expressiva envolvendo deslocamentos de dezenas de quilometros no mínimo e, eventualmente, da ordem de $80 \mathrm{~km}$. A distribuiçăo da intensidade de rejeito 


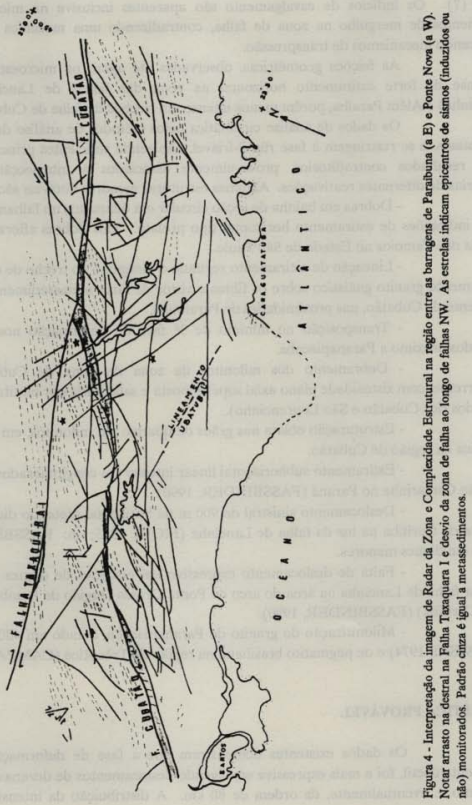




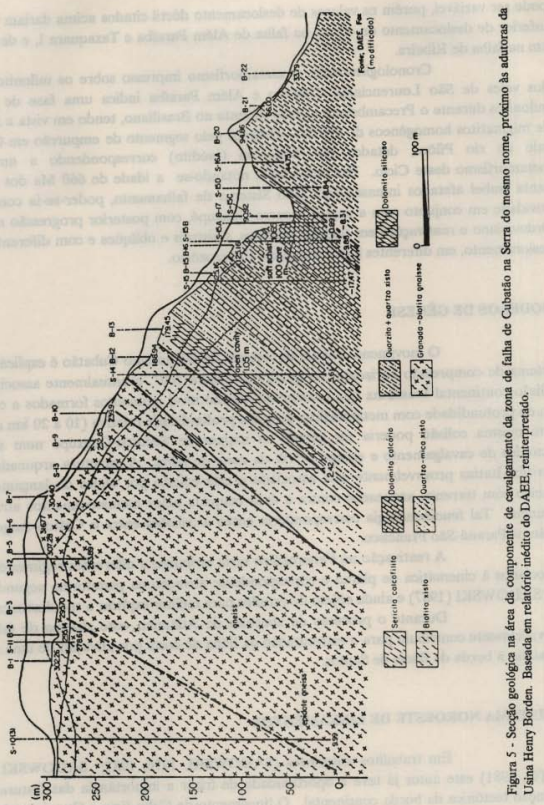


pode ser variável, porém os valores de deslocamento dúctil citados acima dariam um patamar inferior de deslocamento de $40 \mathrm{~km}$ na falha de Além Paraíba e Taxaquara I, e de cerca de 20 $\mathrm{km}$ na falha de Ribeira.

Cronologicamente, o metamorfismo impresso sobre os milonitos nas áreas dos vales de São Lourencinho, Cubatão e Além Paraíba indica uma fase de geração de milonitos durante o Precambriano, provavelmente no Brasiliano, tendo em vista a idade $\mathrm{Rb}-\mathrm{Sr}$ de migmatitos homogêneos de $550 \mathrm{Ma}$, afetados pelo segmento de empurrăo em Cubatăo, no vale do rio Pilōes, datados por Sadowski (inédito) correspondendo a uma fase de metamorfismo deste Ciclo. Por outro lado, notando-se a idade de $660 \mathrm{Ma}$ dos gnaisses de Santa Isabel afetados intensamente pelo Sistema de falhamento, poder-se-ia considerar sua atividade em conjunto com a nappe Socorro-Guaxupé, com posterior progressăo no CambroOrdoviciano e reativaçóes em regimes diversos, sinistrais e oblifuúos e com diferentes taxas de deslocamento, em diferentes locais durante o Fanerozóico.

\section{MODELOS DE GÊNESE}

O movimento destral do sistema de falhamento Cubatáo é explicável por um sistema de compressão horizontal no quadrante $\mathrm{N} 60$ a $100^{\circ}$, eventualmente associado a uma colisấo continental brasiliana que colocou ao mesmo nivel, granulitos formados a cerca de 40 $\mathrm{km}$ de profundidade com metamorficas de baixa profundidade relativa (10 a $20 \mathrm{~km}$ ao menos). Esta mesma colisáo poderia ter gerado as nappes de Socorro-Guaxupé num sistema de tectónica de cavalgamento e escape a NW da zona de falha. A estrutura arqueada no bloco Curitiba-Itatins provavelmente está associada a esta colisão por efeito do lançamento deste maciço com terrenos arqueanos contra a área ocupada pelos metassedimentos atribuídos ao Açungui. Tal fenomenologia corresponderia entâo a colisóes entre o Cráton Angolano e os Crátons Paraná-Săo Francisco.

A reativaçăo no Fanerozóico seria atribuivel a diferentes regimes de esforços associados à cinemática de placas e correspondente ativação da plataforma segundo exposto em SADOWSKI (1987) e ainda objeto de estudos para melhor explicar a sua dinâmica.

Durante o processo de abertura do Atlantico, este sistema de falhamentos provavelmente contribuiu para a estruturação da linha de costa por ativação de uma das falhas paralelas à borda da Bacia de Santos.

\section{O SISTEMA NOROESTE DE LINEAMENTOS}

Em trabalhos anteriores (SADOWSKI, 1976, 1987; SADOWSKI \& DIAS NETO, 1981) este autor já teve a oportunidade de frisar a importância das fraturas NW na evoluçấo tectonica da borda continental. O lineamento de Cabo Frio e Guapiara sáo os mais 
representativos deste sistema. RICCOMINI et al. (1989) comprovou a atividade de uma falha desta direçăo cortando o maciço alcalino de Itatiaia. Na presente análise, lançamos os epicentros de sismos medidos por equipamentos na regiåo de Angra dos Reis e de Paraibuna, tendo observado sua localizaçáo sobre lineamentos de direçăo aproximada N60W (Fig. 4), em resposta a uma componente de compressão ainda a ser definida. Tal sismicidade, bem como a do Rio Grande do Norte, sugerem os efeitos de uma tectonica compressiva atuante na plataforma Sulamericana.

\section{AGRADECIMENTOS}

O autor agradece ao CNPq o auxílio concedido para execuçáo das pesquisas.

\section{REFERÊNCIAS BIBLIOGRÁFICAS}

ALMEIDA, F.F.M. (1975) The system of continental rifts bordering the Santos Basin, Brazil. Anais da Academia Brasileira de Ciências, Suplemento, 48:15-26.

ANDERSON, E.M. (1951) The dynamics of faulting. London. Oliver \& Boyd. 206p.

CAMPANHA, G.A.C. (1981) O lineamento de Além Paraíba na área de Trés Rios (RJ). São Paulo. 109p. (Dissertaçăo de Mestrado, Instituto de Geociências/USP).

CAMPOS NETO, M. \& VASCONCELLOS, A.C. (1985) Relatório FAPESP (inédito).

EBERT, H. (1968) Ocorrencias de fácies granulíticas do sul de Minas Gerais e em áreas adjacentes em dependencia da estrutura orogenica: hipótese sobre sua origem. Anais da Academia Brasileira de Ciências, Suplemento, 40:216-229.

FASSBINDER, E. (1990) Análise estrutural da falha de Lancinha, Estado do Paraná. São Paulo, 165p. (Dissertaçăo de Mestrado, Instituto de Geociências/USP).

FIORI, A.P. (1985) Avaliaçäo preliminar do deslocamento dúctil das falhas da Lancinha e Morro Agudo no Estado do Paraná. Boletim Paranaense de Geociências, 36:15-29.

HASUI, Y.; PONÇANO, W.L.: BISTRICHI, C.A.; STEIN, D.P.: GALVÃO, C.A.C.F.: GIMENEZ, A.F.; ALMEIDA, M.A.; PIRES NETO, A.G.; MELO, M.S.; SANTOS, M.C.S.R. (1978) Geologia da regiâo administrativa 3, Vale do Paraíba e parte da regiâo administrativa 2 đo Estado de São Paulo. Sáo Paulo, IPT. 78p. (Monografia IPT, 1). 
RICCOMINI, C. (1989) O rif continental do Sudeste do Brasil. Sāo Paulo. 256p. (Tese de Doutorado, Instituto de Geociências/USP).

RICCOMINL, C; NEUMANN, R.; MATOS, S.L.F. (1989) Convergent strike-slip faulting in a passive continental margin, southeastern Brazil. In: INTERNATIONAL GEOLOGICAL CONGRESS, 28., Washington, 1989. Abstracts. Washington, International Union of Geological Sciences.

RIDEG, P. (1974) Geology of the Serra do Mar ridge. New York. 189p. (Thesis PhD, University of New York).

SADOWSKI, G.R. (1974) Tectônica da Serra de Cubatáo, SP. São Paulo. 158p. (Tese de Doutorado, Instituto de Geociências/USP).

SADOWSKI, G.R. (1976) Ativaçáo de plataforma na América do Sul e as zonas de fratura do Atlantico Sul. In: CONGRESSO BRASILEIRO DE GEOLOGIA, 29., Ouro Preto, 1976. Anais. Ouro Preto, SBG. V.4, p.13-23.

SADOWSKI, G.R. (1984) Estado da Arte do Tema: Geologia Estrutural de Grandes Falhamentos. In: CONGRESSO BRASIEIRO DE GEOLOGIA, 33., Rio de Janeiro. Anais. Rio de Janeiro, SBG. V.4, p.1767-1793.

SADOWSKI, G.R. (1987) A possible relation between pulses of platform activation and plate kinematics. Tectonophysics, 143(1-3):43-57.

SADOWSKI, G.R. \& DIAS NETO, C.M. (1981) O lineamento sismotecto̊nico de Cabo Frio. Revista Brasileira de Geociências, 11:209-212.

SADOWSKI, G.R. \& MOTIDOME, M.J. (1987) Brazilian megafaults. Revista Geológica do Chile, 31:61-75.

ZALAN, P.V.; WOLFF, S.; CONCEIÇÃO, J.C.J.; ASTOLFI, M.A.M.; VIEIRA, I.S.; APPI, V.T.; ZANOTTO, O.A. (1987) Tectônica e sedimentaçâo da Bacia do Paraná. In: SIMPÓSIO SUL-BRASILEIRO DE GEOLOGIA, 3., Curitiba, 1987. Atas. Curitiba, SBG. V.1, p.441.477. 